\title{
Estimation of the effect-site
}

\author{
Se Yeon Park, Hyun Jung Kim, Yun Suk Choi, So-hui Yun, and \\ Jong Cook Park \\ Department of Anesthesiology and Pain Medicine, Jeju National University Hospital, Jeju, Korea
}

Background: The concept of the effect-site concentration of anesthetic agents is important. The effect compartment model can be explained using the concepts of effect-site concentration and effect-site equilibration rate constant $\left(k_{\mathrm{e} 0}\right)$. This study confirms that the time-to-peak effect $\left(t_{p e}\right)$ can be measured easily in clinical practice by applying a priming dose and train-of-four (TOF) during general anesthesia induction, and $k_{\mathrm{e} 0}$ can be calculated from the $t_{p e}$ of the four muscle relaxants that are commonly used in general anesthesia.

Methods: Eighty patients who received general anesthesia were divided into the succinylcholine, rocuronium, atracurium, or vecuronium groups. Priming doses of muscle relaxants were administered. The effects of muscle relaxants were quantified by recording the twitch response of the adductor pollicis muscle after stimulating the ulnar nerve. The $t_{p e}$ was measured at the lowest TOF value. $k_{\mathrm{e} 0}$ was calculated from the measured $t_{p e}$.

Results: The $k_{\mathrm{e} 0}$ values of the succinylcholine, rocuronium, atracurium, and vecuronium groups were $0.076(0.030) / \mathrm{min}$, $0.228(0.122) / \mathrm{min}, 0.062(0.011) / \mathrm{min}$, and $0.077(0.019) / \mathrm{min}$, respectively.

Conclusions: It is possible to estimate $k_{\mathrm{e} 0}$ from the $t_{p e}$ of muscle relaxants using a priming dose and TOF during general anesthesia induction.

Keywords: Atracurium; General anesthesia; Rocuronium; Succinylcholine; Train-of-four; Vecuronium.

Corresponding author: Jong Cook Park, M.D., Ph.D.

Department of Anesthesiology and Pain Medicine, Jeju National University Hospital, 15, Aran 13-gil, Jeju 63241, Korea

Tel: 82-64-717-2029, Fax: 82-64-717-2042

Email: pjcook@jejunu.ac.kr

ORCID: https://orcid.org/0000-0002-2728-3181

This is a thesis for a Master's degree by Se Yeon Park.

It was presented at the Annual Meeting of the Korean Society for Anesthetic Pharmacology, April 2016, Sejong University, Seoul, Korea.

Received: December 29, 2016. Revised: February 17, 2017 (1st); April 5, 2017 (2nd); May 17, 2017 (3rd). Accepted: May $31,2017$.

Korean J Anesthesiol 2018 April 71(2): 113-119

https://doi.org/10.4097/kjae.2018.71.2.113

(c) This is an open-access article distributed under the terms of the Creative Commons Attribution Non-Commercial License (http://creativecommons.org/ licenses/by-nc/4.0/), which permits unrestricted non-commercial use, distribution, and reproduction in any medium, provided the original work is properly cited. 


\section{Introduction}

The concepts of time and concentration are important for the administration of drugs used in anesthesia. Safe anesthesia is achieved by accurately understanding the effect time of the drug and the dose-response relationship.

The time at which the effect of the drug begins is known as the onset time of the drug. The time at which the effect is maximized is the time-to-peak effect $\left(t_{p e}\right)$. However, since blood is not an effect site of the drug but transports the drug to an effect site, the concept of an effect-site concentration that can represent the effect is needed. When the drug is administered, the plasma concentration gradually decreases from the maximum value, and the effect-site concentration gradually increases. The $t_{p e}$ is the time at which the plasma concentration and the effectsite concentration are equal, and the effect-site concentration is maximum [1].

The effect compartment model was designed to explain the effect-site concentration. The effect-site equilibration rate constant $\left(k_{\mathrm{e} 0}\right)$, which is derived from this model, is the first-order rate constant between the effect site and plasma.

The traditional approaches to calculating the $k_{\mathrm{e} 0}$ are the parametric or sequential pharmacokinetic-pharmacodynamic method and the non-parametric pharmacodynamic modeling. The disadvantage of these methods is the need for a wide range of drug effects, which start at baseline, achieve a maximum effect, and then return to baseline. The calculation of the $k_{\mathrm{e} 0}$ of the drug requires the measurement of the plasma concentration and pharmacokinetic parameters after drug administration combined with the evaluation of the effect of the drug. This approach usually results in an ethically questionable situation or is unfeasible in the clinical setting [2].

The estimation of $k_{\mathrm{e} 0}$ using $t_{p e}$ is an alternative method [2]. $k_{\mathrm{e} 0}$ can be estimated by measuring $t_{p e}$ after the administration of a single-dose or by evaluation of the effect-site concentrationresponse curve during continuous infusion $[3,4]$. We estimated $k_{\mathrm{e} 0}$ from the $t_{p e}$ of muscle relaxants using a single priming dose and train-of-four (TOF) during general anesthesia induction. A priming dose was used because identification of the lowest effect of the drug was not possible with an induction dose.

Knowledge of the $t_{p e}$ and $k_{\mathrm{e} 0}$ of anesthetic agents is important for safe anesthesia. The purpose of this study is to confirm that $t_{p e}$ can be measured easily in clinical practice by applying a priming dose and TOF during general anesthesia induction, and $k_{\mathrm{e} 0}$ can be calculated from the $t_{p e}$ of the four muscle relaxants that are commonly used in general anesthesia.

\section{Materials and Methods}

After receiving approval from the Institutional Review Board
(File No. 2015-12-004-001), a written informed consent was obtained from each patient. Eighty patients who were undergoing elective surgery under general anesthesia for non-systemic diseases such as otitis media and chronic rhinitis were selected by referring to another study [5]. All patients belonged to the American Society of Anesthesiologists (ASA) class 1 or 2. Patients with an ASA class 3 or higher, neuromuscular diseases, liver or kidney diseases, and those without a body mass index of $18.5-30.0 \mathrm{~kg} / \mathrm{m}^{2}$ were excluded. Eighty patients who agreed to the study protocol were randomly divided into the succinylcholine, rocuronium, atracurium, and vecuronium groups. Twenty patients were assigned to each group.

Standard monitoring devices such as non-invasive blood pressure (NIBP), electrocardiogram, and pulse oximetry were used in all patients, who remained in the supine position in the operating room. A kinemyography (KMG) (NMT Mechanosensor, Datex-Ohmeda, Finland) sensor was placed on the thumb and index finger of the arm without the NIBP monitoring device, and electrodes were attached to the wrist where the ulnar nerve passes. After preoxygenation, anesthesia was induced with thiopental sodium $5 \mathrm{mg} / \mathrm{kg}, 100 \%$ oxygen, and 3-5\% sevoflurane. The baseline value was measured by stimulating the ulnar nerve with a maximal stimulation of up to $70 \mathrm{~mA}$, and TOF values were monitored every 10 seconds. The muscle relaxants were diluted with normal saline and were prepared as $10 \mathrm{mg} / \mathrm{ml}$ of succinylcholine chloride, $10 \mathrm{mg} / \mathrm{ml}$ of rocuronium bromide, $10 \mathrm{mg} / \mathrm{ml}$ of atracurium besylate, and $1 \mathrm{mg} / \mathrm{ml}$ of vecuronium bromide. After one-fifth of the muscle relaxant dose used in the induction of general anesthesia was intravenously administered with a priming dose, the time at which the TOF value was the lowest (Fig. 1A) and the effect-site concentration was the highest (Fig. 1B) was measured and recorded. We used $0.2 \mathrm{mg} / \mathrm{kg}$ of succinylcholine, $0.1 \mathrm{mg} / \mathrm{kg}$ of rocuronium, $0.1 \mathrm{mg} / \mathrm{kg}$ of atracurium, and $0.01 \mathrm{mg} / \mathrm{kg}$ of vecuronium as the priming dose. The estimated effect-site equilibration rate constant (estimated $k_{\mathrm{e} 0}$ ) was obtained by using the measured time-to-peak effect (measured $\left.t_{p e}\right)$. The method of Cortínez et al. [2] was used and is described in the Appendix.

When the TOF value increased to more than $20 \%$ of the lowest value, the remaining dose (four-fifths of the total muscle relaxant dose) was intravenously administered. Endotracheal intubation was performed when the TOF value was $0 \%$. Data were collected in real-time using a data collection program $\left(\mathrm{S} / 5^{\circledR}\right.$ collect, Datex-Ohmeda, Finland).

The estimated $k_{\mathrm{e} 0}$ was obtained from the measured $t_{p e}$, and all values were expressed as the mean (SD). Statistical analysis was carried out using Statistical Package for Social Sciences ${ }^{\circledR}$ Statistics version $24\left(\mathrm{IBM}^{\circledR}\right.$, USA). P values smaller than 0.05 were considered statistically significant.

A second objective of the study was the comparison of the 
estimated $k_{\mathrm{e} 0}$ value (obtained from the measured $t_{p e}$ ) with the effect-site equilibration rate constant proposed in other studies (presented $k_{\mathrm{e} 0}$ ) [6-9]. The estimated $t_{p e}$ can be calculated from the presented $k_{\mathrm{e} 0}$ using some equations (detailed in the Appendix). The measured and estimated $t_{p e}$ and the presented and estimated $k_{\mathrm{e} 0}$ within each group were compared using a one-sample
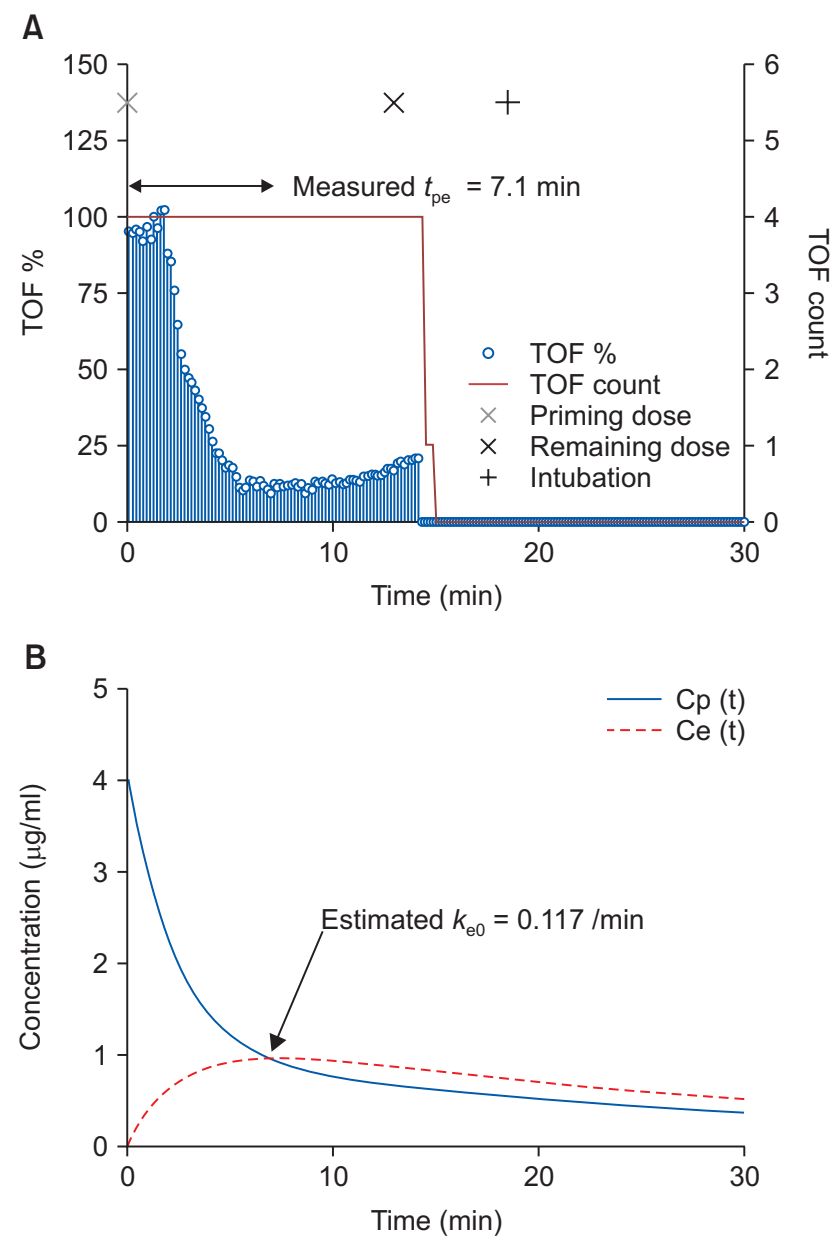

Fig. 1. (A) Graphic representation of the induction-course of a rocuronium-induced non-depolarizing neuromuscular blockade in one patient. Measured $t_{\mathrm{pe}}$ is the time-to-peak effect obtained by using trainof-four (TOF). (B) Concentration and time course of plasma $\mathrm{Cp}(\mathrm{t})$ and effect-site $\mathrm{Ce}(\mathrm{t})$. Estimated $k_{e 0}$ is the value calculated using the measured time-to-peak effect. t-test.

\section{Results}

The patient characteristics of the four muscle relaxant groups are shown in Table 1. There were no significant differences in these variables between the groups.

The measured $t_{p e}$ of each group was $2.2(0.4) \mathrm{min}$ in the succinylcholine group, 5.1 (1.7) $\mathrm{min}$ in the rocuronium group, 9.6 (1.5) $\mathrm{min}$ in the atracurium group, and $9.6(2.1) \mathrm{min}$ in the vecuronium group. The estimated $k_{\mathrm{e} 0}$ was $0.076(0.030) / \mathrm{min}$ in the succinylcholine group, $0.228(0.122) / \mathrm{min}$ in the rocuronium group, $0.062(0.011) / \mathrm{min}$ in the atracurium group, and 0.077 $(0.019) / \mathrm{min}$ in the vecuronium group.

Table 2 presents the results of the comparison of the estimated $k_{\mathrm{e} 0}$ and measured $t_{p e}$ with the effect-site equilibration rate constant proposed in other studies (presented $k_{\mathrm{e} 0}$ ) [6-9] and the time-to-peak effect, which is calculated from the presented $k_{\mathrm{e} 0}$ (estimated $t_{p e}$ ). The $t_{p e}$ of the succinylcholine group and the $k_{\mathrm{e} 0}$ of the vecuronium group were not significantly different, but these variables were significantly different in the other groups.

\section{Discussion}

Knowledge about the $t_{p e}$ and $k_{\mathrm{e} 0}$ of anesthetic agents is important for safe anesthesia. Identification of the time of onset of a drug is easy clinically, but the determination of $t_{p e}$ is not easy. This study was designed to easily obtain the $t_{p e}$ and $k_{\mathrm{e} 0}$ of anesthetic agents in clinical practice. In general anesthesia induction involving a priming dose, TOF was used to measure $t_{p e}$. We developed a program using Excel ${ }^{\circledR} 2007$ (Microsoft, USA) software with equations (shown in the Appendix) that can calculate $k_{\mathrm{e} 0}$ from $t_{p e} \cdot k_{\mathrm{e} 0}$ is estimated when $t_{p e}$ is input to the program. The study design and the program can be simulated to obtain the $k_{\mathrm{e} 0}$ of other drugs, and herein we estimated the $k_{\mathrm{e} 0}$ of the four muscle relaxants that are commonly used in anesthesia. The measured $t_{p e}$ of the muscle relaxants was obtained by TOF monitoring during general anesthesia induction and administering a priming dose of each muscle relaxant. According to the principle of linear pharmacokinetics, because plasma concentration or

Table 1. Patient Characteristics

\begin{tabular}{lcccc}
\hline & $\begin{array}{c}\text { Succinylcholine group } \\
(\mathrm{n}=20)\end{array}$ & $\begin{array}{c}\text { Rocuronium group } \\
(\mathrm{n}=20)\end{array}$ & $\begin{array}{c}\text { Atracurium group } \\
(\mathrm{n}=20)\end{array}$ & $\begin{array}{c}\text { Vecuronium group } \\
(\mathrm{n}=20)\end{array}$ \\
\hline Age $(\mathrm{yr})$ & $48(17)$ & $47(16)$ & $48(17)$ & $51(11)$ \\
Sex $(\mathrm{M} / \mathrm{F})$ & $13 / 7$ & $13 / 7$ & $14 / 6$ & $7 / 13$ \\
Body weight $(\mathrm{kg})$ & $64.7(13.1)$ & $65.5(14.7)$ & $65.8(8.3)$ & $64.2(12.5)$ \\
Height $(\mathrm{cm})$ & $163.7(10.6)$ & $162.5(11.6)$ & $164.9(7.3)$ & $160.0(8.3)$ \\
\hline
\end{tabular}

Values are expressed as mean (SD). 
Table 2. Comparison of the Time-to-peak Effect $\left(t_{p e}\right)$ and the Effect-site Equilibration Rate Constant $\left(k_{\mathrm{e} 0}\right)$ for Each Muscle Relaxant

\begin{tabular}{|c|c|c|c|c|}
\hline & $\begin{array}{l}\text { Succinylcholine group } \\
\qquad(\mathrm{n}=20)\end{array}$ & $\begin{array}{l}\text { Rocuronium group } \\
\qquad(\mathrm{n}=20)\end{array}$ & $\begin{array}{l}\text { Atracurium group } \\
\qquad(\mathrm{n}=20)\end{array}$ & $\begin{array}{l}\text { Vecuronium group } \\
\qquad(\mathrm{n}=20)\end{array}$ \\
\hline $\begin{array}{c}\text { Measured } t_{p e}(\min ) \\
\downarrow\end{array}$ & $2.2(0.4)$ & $5.1(1.7)$ & $9.6(1.5)$ & $9.6(2.1)$ \\
\hline Estimated $k_{\mathrm{e} 0}(/ \mathrm{min})$ & $0.076(0.030)$ & $0.228(0.122)$ & $0.062(0.011)$ & $0.077(0.019)$ \\
\hline$\underset{\uparrow}{\text { Estimated } t_{p e}(\min )}$ & 2.3 & 6.3 & 8.7 & 8.4 \\
\hline Presented $k_{\mathrm{e} 0}(/ \mathrm{min})$ & 0.058 & 0.127 & 0.068 & 0.085 \\
\hline P value* & 0.127 & 0.005 & 0.013 & 0.020 \\
\hline $\mathrm{P}_{\text {value }}{ }^{\dagger}$ & 0.013 & 0.002 & 0.027 & 0.066 \\
\hline
\end{tabular}

Values are expressed as mean (SD). Measured $t_{p e}$ is the $t_{p e}$ obtained by using train-of-four (TOF). Estimated $k_{\mathrm{e} 0}$ is the value calculated using the measured $t_{p e}$. Estimated $t_{p e}$ is the value calculated using the presented $k_{\mathrm{e} 0}$. Presented $k_{\mathrm{e} 0}$ is the $k_{\mathrm{e} 0}$ proposed in other studies. References of the presented $k_{\mathrm{e} 0}(/ \mathrm{min})$ : succinylcholine [6], rocuronium [7], atracurium [8], vecuronium [9]. $\rightarrow$ : the direction of calculation, $t_{p e}$ (min): time-to-peak effect, $k_{\mathrm{e} 0}$ (/min): effect-site equilibration rate constant. * Comparison of the measured $t_{p e}$ and the estimated $t_{p e}{ }^{\dagger}$ Comparison of the presented $k_{\mathrm{e} 0}$ and the estimated $k_{\mathrm{e} 0}$.

elimination is proportional to the dose, $k_{\mathrm{e} 0}$ is not affected [10]. Therefore, $k_{\mathrm{e} 0}$ can be obtained by the intravenous administration of the priming dose.

The TOF stimulation method is used to determine the quantitative relationship between the effect-site concentration and the drug effect. After bolus administration of the muscle relaxant, the time at which the TOF value is the lowest is the $t_{p e}$. The advantages of TOF stimulation are its noninvasiveness, ease of use, and cost-effectiveness. TOF stimulation has been applied with a minimum interval of 10 seconds and is known to be more sensitive than single twitch [11-13]. In addition, TOF stimulation is more advantageous than single twitch because the latter needs to establish a baseline value before the administration of muscle relaxants. Mechanomyography (MMG) has long been regarded as the gold standard of neuromuscular monitoring, but the mechanomyogram is relatively bulky and difficult to apply, which limits its clinical use $[14,15]$. The KMG used in this study can be easily applied in clinical practice without significant differences from the results of MMG, electromyography (EMG), acceleromyography, and phonomyography [15-17]. However, some studies suggest that KMG rather than EMG is overestimated [18], which may be a limitation of this study.

The determination of the estimated $k_{\mathrm{e} 0}$ from the measured $t_{p e}$ only requires a portion of the response curve, without the need to evaluate the complete course of the drug effect, and is possible by measuring the drug effect during general anesthesia induction [19]. Excel ${ }^{\circledR} 2007$ (Microsoft, USA) software was used to calculate the estimated $k_{\mathrm{e} 0}$ rather than an expensive commercial program. Excel ${ }^{\circledR}$ is relatively easy to use to obtain the estimated $k_{\mathrm{e} 0}$ from the measured $t_{p e}$ and the estimated $k_{\mathrm{e} 0}$ can be simulated for drugs other than muscle relaxants.

Since the drug volume of distribution in the effect site can be determined from the $k_{\mathrm{e} 0}$, the initial loading dose and $t_{p e}$ can be obtained, and additional dosages and time points can be determined. Therefore, $k_{\mathrm{e} 0}$ of muscle relaxants is important in general anesthesia. In other words, the $t_{p e}$ and $k_{\mathrm{e} 0}$ of muscle relaxants are used clinically to determine the timing of intubation of each muscle relaxant and help to determine when additional doses should be administered during anesthetic maintenance. $k_{\mathrm{e} 0}$ can also be used for target-controlled infusion [1].

Because the estimated $k_{\mathrm{e} 0}$ was obtained from the measured $t_{p e}$ of the four muscle relaxants commonly used in general anesthesia, it has significance as the estimated $k_{\mathrm{e} 0}$ of each muscle relaxant in the same study design. Our results indicated a variation in the measured $t_{p e}$ for each patient even with the same muscle relaxant. Since the estimated $k_{\mathrm{e} 0}$ was obtained from each measured $t_{p e}$, the former was also affected by an individual bias. However, even in cases in which the same drug was administered at the same dose, the effects were different for each patient because of the pharmacokinetic and pharmacodynamic variability [1]. Pharmacokinetic variability is defined as the condition in which a time-concentration curve varies from person to person. Pharmacodynamic variability is defined as a condition in which a response varies from person to person at the same concentration. This limitation can be overcome by population analysis. However, although studies have suggested the various pharmacokinetic parameters, we selected the same pharmacokinetic parameters for each group of muscle relaxant [6,20-22]. Therefore, it was thought that there was no variation in the estimation of the $k_{\mathrm{e} 0}$ by using pharmacokinetic parameters.

The second objective of our study was to compare the $t_{p e}$ and $k_{\mathrm{e} 0}$ of other studies with the $t_{p e}$ and $k_{\mathrm{e} 0}$ of our study to support the accuracy of our results. The $t_{p e}$ of the succinylcholine group and the $k_{\mathrm{e} 0}$ of the vecuronium group were not significantly different, but these variables were significantly different in the other groups (Table 2). In the rocuronium group, the presented 
$k_{\mathrm{e} 0}$ that we quoted in another study was $0.127 / \mathrm{min}$, but $k_{\mathrm{e} 0}$ values suggested in that study were $0.127 / \mathrm{min}$ and $0.09 / \mathrm{min}$ [7]. For atracurium, a study suggests a $k_{\mathrm{e} 0}$ of $0.043 / \mathrm{min}$ [23], the other study proposes $0.068 / \mathrm{min}$. The difference between this study and other studies is the use of isoflurane or propofol as the anesthetic agent as well as the use of TOF or single twitch. As inhalation anesthetics enhance the effect of muscle relaxation, they likely affect the muscle relaxation effect. TOF stimulation and single twitch were considered study variants with a high sensitivity but a low specificity.

The estimated $k_{\mathrm{e} 0}$ was compared with the presented $k_{\mathrm{e} 0}$, and the estimated $t_{p e}$ (calculated from the presented $k_{\mathrm{e} 0}$ ) was verified by using the measured $t_{p e}$. In this study, the estimated $k_{\mathrm{e} 0}$ of succinylcholine, rocuronium, and atracurium was different from the presented $k_{\mathrm{e} 0}$. Further studies are necessary to elucidate these results.

In conclusion, this study was designed to easily obtain the $t_{p e}$ and $k_{\mathrm{e} 0}$ of anesthetic agents in clinical practice. The study design and the program can be simulated to obtain the $k_{\mathrm{e} 0}$ of other drugs, and we estimated the $k_{\mathrm{e} 0}$ of the four muscle relaxants that are commonly used in anesthesia. The estimated $k_{\mathrm{e} 0}$ can be obtained from the measured $t_{p e}$ of these four muscle relaxants using a priming dose and TOF stimulation during general anesthesia induction, and individual deviations in $t_{p e}$ and $k_{\mathrm{e} 0}$ are observed.

\section{Acknowledgments}

This research was supported by the 2017 scientific promotion program funded by Jeju National University.

\section{ORCID}

Hyun Jung Kim, https://orcid.org/0000-0002-4852-7165

Yun Suk Choi, https://orcid.org/0000-0002-7983-8089

So-hui Yun, https://orcid.org/0000-0001-9544-5085

Jong Cook Park, https://orcid.org/0000-0002-2728-3181

\section{References}

1. Han DW. Pharmacokinetic and pharmacodynamic modeling in anesthetic field. Anesth Pain Med 2014; 9: 77-86.

2. Cortínez LI, Nazar C, Muñoz HR. Estimation of the plasma effect-site equilibration rate constant (ke0) of rocuronium by the time of maximum effect: a comparison with non-parametric and parametric approaches. Br J Anaesth 2007; 99: 679-85.

3. Minto CF, Schnider TW, Gregg KM, Henthorn TK, Shafer SL. Using the time of maximum effect site concentration to combine pharmacokinetics and pharmacodynamics. Anesthesiology 2003; 99: 324-33.

4. van Meurs WL, Nikkelen E, Good ML. Pharmacokinetic-pharmacodynamic model for educational simulations. IEEE Trans Biomed Eng 1998; 45: 582-90.

5. Park JC, Park KS. Comparison of pharmacodynamics and intubation conditions of muscle relaxants using a continuous infusion during induction. Korean J Anesthesiol 2006; 50: 250-5.

6. Roy JJ, Donati F, Boismenu D, Varin F. Concentration-effect relation of succinylcholine chloride during propofol anesthesia. Anesthesiology 2002; 97: 1082-92.

7. Dragne A, Varin F, Plaud B, Donati F. Rocuronium pharmacokinetic-pharmacodynamic relationship under stable propofol or isoflurane anesthesia. Can J Anaesth 2002; 49: 353-60.

8. Donati F, Gill SS, Bevan DR, Ducharme J, Theoret Y, Varin F. Pharmacokinetics and pharmacodynamics of atracurium with and without previous suxamethonium administration. Br J Anaesth 1991; 66: 557-61.

9. Alloul K, Whalley DG, Shutway F, Ebrahim Z, Varin F. Pharmacokinetic origin of carbamazepine-induced resistance to vecuronium neuromuscular blockade in anesthetized patients. Anesthesiology 1996; 84: 330-9.

10. Park JC. How to design intravenous anesthetic dose regimens based on pharmacokinetics and pharmacodynamics principles. Anesth Pain Med 2015; 10: 235-44.

11. Ali HH, Utting JE, Gray TC. Quantitative assessment of residual antidepolarizing block. I. Br J Anaesth 1971; 43: 473-7.

12. Ali HH, Utting JE, Gray TC. Quantitative assessment of residual antidepolarizing block. II. Br J Anaesth 1971; 43: 478-85.

13. Morgan GE, Mikhail MS, Murray MJ, Kleinman W, Nitti GJ, Nitti JT, et al. Clinical Anesthesiology. 5th ed. New York, McGraw-hill. 2002, p 228.

14. Jung W, Hwang M, Won YJ, Lim BG, Kong MH, Lee IO. Comparison of clinical validation of acceleromyography and electromyography in children who were administered rocuronium during general anesthesia: a prospective double-blinded randomized study. Korean J Anesthesiol 2016; 69: 21-6

15. Gaffar EA, Fattah SA, Atef HM, Omera MA, Abdel-Aziz MA. Kinemyography (KMG) versus Electromyography (EMG) neuromuscular monitoring in pediatric patients receiving cisatracurium during general anesthesia. Egypt J Anaesth 2013; 29: 247-53.

16. Trager G, Michaud G, Deschamps S, Hemmerling TM. Comparison of phonomyography, kinemyography and mechanomyography for neuromuscular monitoring. Can J Anaesth 2006; 53: 130-5. 
17. Son HJ, Lee JH, Park SW, Cho DS. The comparison among mechanical, electromyographic and accelerographic responses during recovery from vecuronium induced neuromuscular blockade. Korean J Anesthesiol 1993; 26: 910-8.

18. Salminen J, van Gils M, Paloheimo M, Yli-Hankala A. Comparison of train-of-four ratios measured with Datex-Ohmeda’s M-NMT MechanoSensor $^{\mathrm{TM}}$ and M-NMT ElectroSensor ${ }^{\mathrm{TM}}$. J Clin Monit Comput 2016; 30: 295-300.

19. Billard V, Gambus PL, Chamoun N, Stanski DR, Shafer SL. A comparison of spectral edge, delta power, and bispectral index as EEG measures of alfentanil, propofol, and midazolam drug effect. Clin Pharmacol Ther 1997; 61: 45-58.

20. Wierda JM, Kleef UW, Lambalk LM, Kloppenburg WD, Agoston S. The pharmacodynamics and pharmacokinetics of Org 9426, a new nondepolarizing neuromuscular blocking agent, in patients anaesthetized with nitrous oxide, halothane and fentanyl. Can J Anaesth 1991; 38: 430-5.

21. Kitts JB, Fisher DM, Canfell PC, Spellman MJ, Caldwell JE, Heier T, et al. Pharmacokinetics and pharmacodynamics of atracurium in the elderly. Anesthesiology 1990; 72: 272-5.

22. Sohn YJ, Bencini AF, Scaf AH, Kersten UW, Agoston S. Comparative pharmacokinetics and dynamics of vecuronium and pancuronium in anesthetized patients. Anesth Analg 1986; 65: 233-9.

23. Roy JJ, Varin F. Physicochemical properties of neuromuscular blocking agents and their impact on the pharmacokinetic-pharmacodynamic relationship. Br J Anaesth 2004; 93: 241-8. 


\section{Appendix}

The plasma concentration $\left(C_{p}\right)$ is a composite convolution of the dosage regimen $(D)$ and the unit disposition function $(U D F)$. $C_{p}$ can be summarized by the following equation:

$$
C_{p}(t)=D(t) \otimes U D F(t)
$$

where $\otimes$ represents a convolution. When $t$ is 0 and $D$ is $1, C_{p}(t)$ becomes $U D F(t)$. The $U D F(t)$ of the multi-compartment model is presented by the following equation [10]:

$$
U D F(t)=\sum_{i=1}^{n} A_{i} \times e^{-\lambda_{i} \times t}
$$

Equation 2

where $A_{i}$ is the coefficient and $\lambda_{i}$ is the exponent, and these variables are obtained from the volume $\left(V_{i}\right)$ and the micro-rate constant $\left(k_{i j}\right)$ shown in Table A.

In the compartment models, the effect-site compartment includes the effect-site equilibration rate constant $\left(k_{e 0}\right)$, and the volume of the effect site and the drug movement with the central compartment are negligible. The effect-site concentration $\left(C_{e}\right)$ is represented by the following equation [10]:

$$
C_{e}(t)=D(t) \otimes \sum_{i=1}^{n} \frac{k_{e 0} \times A_{i}}{k_{e 0}-\lambda_{i}} \times\left(e^{-\lambda_{i} \times t}-e^{-k_{e 0} \times t}\right)
$$

Since the rate of increase or decrease of the effect-site concentration is 0 at the time-to-peak effect $\left(t_{p e}\right)$, when $C_{e}^{\prime}(t)$ is $0, t$ is $t_{p e}$. The $t_{p e}$ is estimated by substituting $k_{\mathrm{e} 0}$ into the following equation [10]:

$$
C_{e}^{\prime}(t)=D(t) \otimes \sum_{i=1}^{n} \frac{k_{e 0} \times A_{i}}{k_{e 0}-\lambda_{i}} \times\left(\lambda_{i} \times e^{-\lambda_{i} \times t}-k_{e 0} \times e^{-k_{e 0} \times t}\right)=0
$$

In contrast, $k_{\mathrm{e} 0}$ can be estimated from the measured $t_{p e}$. Considering that the plasma concentration and the effect-site concentration are in equilibrium at the measured $t_{p e}, k_{\mathrm{e} 0}$ can be calculated by the following equation [10]:

$$
\left\{C_{p}\left(t_{p e}\right)-C_{e}\left(t_{p e}\right)\right\}^{2} \cong 0
$$

These equations were used in Excel ${ }^{\circledR} 2007$ (Microsoft, USA) to construct a simulation program. The program can calculate $t_{p e}$ using $k_{e 0}$, and can derive $k_{e 0}$ by substituting $t_{p e}$. The pharmacokinetic parameters used for each muscle relaxant are shown in Table A.

Table A. Pharmacokinetic Parameters of Muscle Relaxants

\begin{tabular}{lcccc}
\hline & $\begin{array}{c}\text { Succinylcholine: } \\
\text { Roy et al. [6] }\end{array}$ & $\begin{array}{c}\text { Rocuronium: } \\
\text { Wierda et al. [20] }\end{array}$ & $\begin{array}{c}\text { Atracurium: } \\
\text { Kitts et al. [21] }\end{array}$ & $\begin{array}{c}\text { Vecuronium: } \\
\text { Sohn et al. [22] }\end{array}$ \\
\hline$k_{10}(/ \mathrm{min})$ & $5.0(2.6)$ & 0.1 & 0.166 & $0.099(0.049)$ \\
$k_{12}(/ \mathrm{min})$ & $2.9(3.9)$ & 0.21 & 0.217 & $0.23(0.18)$ \\
$k_{21}(/ \mathrm{min})$ & $1.6(0.4)$ & 0.13 & 0.123 & $0.19(0.12)$ \\
$k_{13}(/ \mathrm{min})$ & - & 0.028 & - & $0.086(0.024)$ \\
$k_{31}(/ \mathrm{min})$ & - & 0.01 & - & $0.013(0.007)$ \\
$V_{1}(\mathrm{~L} / \mathrm{kg})$ & $0.009(0.003)$ & 0.045 & 0.032 & $0.048(0.02)$ \\
$V_{2}(\mathrm{~L} / \mathrm{kg})$ & 0.016 & 0.073 & 0.068 & $0.054(0.031)$ \\
$V_{3}(\mathrm{~L} / \mathrm{kg})$ & - & 0.126 & - & $0.38(0.22)$ \\
\hline
\end{tabular}

All data presented as mean (SD). $k_{i j}(/ \mathrm{min})$ : micro-rate constant. $V_{i}(\mathrm{~L} / \mathrm{kg})$ : volume of distribution of the three compartments. 